\title{
INDIVIDUAL WORK PERFORMANCE MANAGEMENT MODEL
}

\author{
Veingerl Cic, Z.; Vujica Herzog, N. ${ }^{* *} \&$ Macek, A.**** \\ * Doba Business School, Presernova 1, 2000 Maribor, Slovenia \\ ${ }^{* *}$ University of Maribor, Faculty of Mechanical Engineering, Smetanova 17, 2000 Maribor, Slovenia \\ ${ }^{* * *}$ FH Joanneum Graz, Alte Poststraße 149, 8020 Graz, Austria \\ E-Mail: ziva.veingerl-cic@doba.si,natasa.vujica@um.si,anita.macek@fh-joanneum.at
}

\begin{abstract}
Turbulent business environment with constant changes and challenges is forcing organizations to take actions that will allow them to become more manoeuvrable and more flexible. Long-term and holistic approach to employee development is vital for achieving the performance of individuals and of the organization as a whole. This paper aims to explore the linkages between the individual constructs of the conceptual model on individual performance management of employees. The research was performed on the sample of Slovenian service sector companies. A nonlinear structural equation modelling analysis was conducted with the WarpPLS 5.0 based on the Warp2 algorithm. The results show that the use of comprehensive employee development methods significantly positively influences employees' satisfaction at work, individual performance, and psychic well-being.

(Received in November 2019, accepted in February 2020. This paper was with the authors 1 month for 1 revision.)
\end{abstract}

Key Words: Individual Employee Performance Management, Nonlinear Connections, Service Sector, Structural Equation Modelling, WarpPLS 5.0

\section{INTRODUCTION}

Although the methods of work in organizations have dramatically changed in recent years, the process of performance management in many organizations remained the same. According to [1], traditional methods of performance management are ineffective and have failed as a method for managing of employees' performance because such methods demoralize employees, create hatred among them, and encourage prospective and key employees (talents) to start looking for work elsewhere. The fundamental issue is identifying methods by which employee performance management can increase the individual performance of employees and positively influence the mental well-being and satisfaction of employees.

In this paper attention is focused on the nonlinear connections between the individual constructs of the conceptual model on individual performance management of employees using the structural equation modelling (SEM) tool WarpPLS 5.0 together with the quality of the model based on nonlinear connections. The case presents the individual performance management system in the survey among employees in service sector companies in Slovenia.

In this study, authors focused on individual employee performance management. Individual constructs of the conceptual model are comprehensive employee development methods (CDM) such as coaching, mentoring, intergenerational cooperation, and sponsorship; employee satisfaction at work (SAT); psychic well-being (PWB), and individual work performance (IWP). After introduction in the second section authors present theoretical background of IWP and in third section the development of research question and hypothesis. In fourth section the research methodology is presented, while in fifth and sixth section results of the empirical research on IWP in Slovenian service sector companies are described and discussed. Last section brings concluding remarks together with research limitations and further research possibilities. 


\section{LITERATURE REVIEW}

\subsection{Individual work performance}

The IWP model addresses a problem within human resource management; it covers IWP management with CDM in terms of PWB and employee satisfaction. The model applies to the service sector organizations, as authors started from the assumption that we are in a knowledge society and that more than $70 \%$ of employees work in the services sector.

IWP is a multi-dimensional construct with three generic dimensions [2]. The first dimension is task performance, which refers to the professionalism with which employees perform their core working tasks. It can be defined as the proficiency (i.e., competency) with which one performs central job tasks and includes, for example, work quantity, work quality, and job knowledge [2]. The second dimension is contextual performance. It relates to employee behaviour that supports the organizational, social, and psychological environment in which central work tasks take place. Counterproductive behaviour, the third dimension, is detrimental to the well-being of employees and the organization and includes behaviours such as complaining, doing actions endangering the organization, misusing information, time and resources, conflicts with colleagues, deviant behaviour, destructive/dangerous behaviour, poor quality of work and abuse of various substances in the workplace [3]. These three types of IWP dimensions capture the full spectrum of behaviours that represent an individual's performance [4].

The importance and key role of employee performance management is to ensure that organizations are proactive in identifying and designing change with trained employees that have the knowledge and behaviour that is necessary $[4,5]$.

\subsection{Comprehensive employee development methods}

CDM include mentoring, coaching, sponsorship, and intergenerational cooperation as ways of developing the employees' skills. The definition of CDM stems from findings, that integrity/holism includes the whole, parts, relationships, and realism as a system (all methods are grouped under a single concept of CDM of employees). Therefore, with CDM, authors approach the development of intrapersonal methods of individuals in a comprehensive/holistic way: The coherent and integrated functioning of methods contributes to the personal development of the individual, who becomes even more comprehensive with the development of potentials and abilities. When designing CDM, authors followed the work of those authors who advocate the importance of strategic workplace relationships, which CDM encourage [6].

CDM affect employees' psychic well-being, satisfaction, and success, although CDM should primarily reduce the gap between abilities, knowledge, values, and desirable forms of behaviour [6, 7]. Individuals use CDM to develop new skills, create a better identity, and more easily face changes and challenges.

\subsection{Psychic well-being}

Psychic well-being (PWB) is a multidimensional concept that can be divided into three models: subjective emotional well-being, psychological well-being, and self-determination. Everyone wants to feel well at work and be healthy, but this is often difficult to achieve in the modern business world, as there is often a mismatch between an individual's desires for his/her well-being and the daily work overload and stress at work. As a concept, PWB has close links to IWP management, as many authors have found that employees' positive mental and physic well-being is associated with better results of IWP [8]. Positive subjective wellbeing also affects IWP and corporate performance. Within the complexity of today's society, 
employees need a sense of security and well-being in their workplace; otherwise, their psychological energy would be focused elsewhere [9].

Performance management systems support the development of employees, and use of CDM influences employees' PWB as they reduce stress, increase awareness and selfawareness, which improves physical health and well-being [10].

\subsection{Employee satisfaction at work}

Employee satisfaction at work is a multidimensional concept, covering employees' psychological responses to their workplace [11]. The dimensions of employee satisfaction include general satisfaction, internal satisfaction, and external satisfaction. All three forms of satisfaction have close links to internal and external motivational factors. Jayasuriya et al. [12] have defined satisfaction at the workplace as a pleasant and positive emotional reaction to the individual's experience with his/her work, importance of the inner perception of his/her values, and their connection with his/her perception of current working conditions. Many researchers have clearly associated different methods of employee development with increasing employee satisfaction at work and happy employees [12, 13].

Research shows that employee satisfaction is largely based on PWB at work and that satisfaction at work and PWB occur more when individuals feel they are performing better than usual [9]. Outcomes of a better fit between the employee and the job include better job performance and higher job satisfaction and the employees with a positive PWB are more satisfied with their work [14].

\section{DEVELOPMENT OF RESEARCH QUESTION AND HYPOTHESES}

With the help of theoretical knowledge and lessons from the empirical research, authors tried to answer the following research question:

RQ: What is the impact of introducing the individual work performance (IWP) management model of employees by using the comprehensive methods of employee development $(\mathrm{CDM})$ to their satisfaction in the workplace, psychic well-being (PWB), and individual work performance?

\subsection{Individual work performance and comprehensive employee development methods}

Kraimer et al. [15] studied the role of employee attitudes and employee development perceptions, in connection with the results of the IWP. Employee development is an integral part of performance management because it is directly related to the individual's everyday experience By promoting learning through workplace practice, CDM directly stimulate learning at work and behaviour toward individual performance [16].

Hypothesis 1: Comprehensive employee development methods have a positive impact on individual work performance.

\subsection{Comprehensive employee development methods and psychic well-being}

An individual's learning desire and ability are key concepts in understanding the effectiveness of developmental relationships. Potential psychological benefits of CDM are improved selfconfidence, self-image, and self-efficacy of employees. Development intentions and the need and motivation for achievement are important for long-term survival, development and success [17]. CDM improve physical health, PWB, and the permanently desired change of the individual [18]. Therefore, authors highlight CDM's link with PWB.

Hypothesis 2: Comprehensive employee development methods have a positive impact on psychic well-being. 


\subsection{Comprehensive employee development methods and satisfaction in the workplace}

There is evidence of a positive relationship between CDM and job satisfaction, as CDM provide a sense of sophistication and complacency and affect quality improvement of work life [7]. Many researchers [13] have noted that the use of CDM increases the productivity of the organization and brings financial benefits; it also increases employees' satisfaction at work. A positive link exists between the development perceptions of the employees and their satisfaction at work because satisfaction at the workplace is employees' assessment regarding their feelings related to work [19].

Hypothesis 3: Comprehensive employee development methods have a positive impact on employee satisfaction.

\subsection{Employee satisfaction at work and psychic well-being}

Studies have shown that happy employees are more involved in work roles and have higher job satisfaction [20]. Positive experiences and subjective well-being and opportunities for promotion [15] are also an important part of promotion, as is increasing workplace satisfaction and reducing the feelings of emotional distress. Consistent with Fredrickson's model, performance is highest when employees report high scores on both PWB and job satisfaction.

Hypothesis 4: Psychic well-being has a positive impact on employee satisfaction at work.

\subsection{Individual work performance and employee satisfaction at work}

Employees who have a high level of job satisfaction generally love their job and, when they are happy at work, will even devote private time to their work activities [21]. Research results have revealed a positive correlation between job satisfaction and individual performances [22]. Although studies have shown that motivation, work satisfaction, and work performance are interconnected and interdependent, their relationship is not linear but circular [23, 24]. We can conclude that effective IWP management systems not only improve the performance, but also contribute to positive well-being, as it increases overall job satisfaction.

Hypothesis 5: Individual work performance has a positive impact on employee satisfaction at work.

\section{METHODOLOGY}

For the development of a measurement instrument for the constructs of the conceptual model of the individual performance management of employees' authors used an existing and validated measurement instrument, which was adapted to the Slovenian context. The measurement instruments used were:

- Individual Work Performance Questionnaire [4];

- Short version of Minnesota Satisfaction Questionnaire [25];

- PANAS [26];

- Scales of Psychological Well-Being Measure [27];

- Satisfaction with Life Scale [28]; and

- Self-determination Questionnaire [29].

The research took place in Slovenian business services companies. Based on a random selection, 320 organizations were included in the final sample, considering the $95 \%$ confidence level and $5 \%$ standard error; $236(74 \%)$ of them were micro and small companies, $74(23 \%)$ were middle-sized, and $10(3 \%)$ were large companies. 
The questionnaire was created in an electronic form using the open-source Web application $1 \mathrm{Ka}$. A 5-point Likert scale, ranging from 1 (absolutely disagree) to 5 (completely agree), was used. The questionnaire consisted of 14 questions.

The survey was carried out from May 1, 2019, to September 30, 2019. The collected data were processed using IBM SPSS 23.0 and WarpPLS 5.0.

For data analysis authors applied SEM and used the software tool WarpPLS 5.0 as it identifies the nonlinear relationship among the studied latent variables. The basic measured conceptual model was evaluated in terms of reliability and validity. With the help of the variance inflation factor $(V I F)$, multicollinearity was examined. Composite reliability was measured with Cronbach's $\alpha$, which was in our case greater than 0.6. Convergent validity was measured with the coefficient $A V E$ (average of the excluded variances). For the study of discriminatory validity, the maximum shared variance $(M S V)$ and average shared variance $(A S V)$ indices were used. Nomological validity was evaluated by using the correlation between the constructs with which the consistency of theoretical constructs was verified. Here, the criteria that the correlation coefficients are statistically significant [30] were taken into account. The final research model was checked with the goodness of fit $(G o F)$ index.

\section{RESULTS}

For the purpose to build a model for the study of individual performance management of employees based on the linear connections, we used the Smart PLS tool where the quality assessment of key indicators of a conceptual model was lower (not statistically significant, $p>0.05$ ) than those obtained with WarpPLS 5.0. Because the indicators showed no significant connections between the constructs, we used WarpPLS 5.0 to examine the nonlinear connections between the constructs. In the context of the SEM, the model consistency was verified using the GoF index, keeping in mind the criteria of $0.1,0.25$, and 0.36 .

While linear relationships between the pairs of latent variables are relatively easy to interpret, nonlinear relations between the latent variables could provide a much more nuanced view of the data and are much more difficult to explain. Fig. 1 presents the relationships between the basic constructs in conceptual model.

Four latent variables PWB, CDM, SAT, IWP and their relationships are presented in separated graphs. The curve in the first graph shows the relationship between PWB and CDM, while the second graph shows the relationship between SAT and CDM. It can be seen that relationships between the mentioned variables are nonlinear. Further, the third graph shows the relationship between SAT and PWB, the fourth the relationship between IWP and CDM, and the last graph shows the relationship between SAT and IWP. Even the shapes of curves in these graphs are different they all show nonlinear relationships between the latent variables.

Values of the Cronbach's $\alpha$ were higher than 0.6 except for the individual employee performance construct, where the Cronbach's $\alpha$ is slightly below $0.6(0.596)$. Based on these values, authors met the criterion for demonstrating the reliability of the measurement instrument. When checking the reliability of the composite, authors considered that all $C R$ values of all constructs were higher than 0.6. This criterion was met, as all $C R$ values in individual constructs were higher than 0.7 . When verifying the convergent validity measured with $A V E$, authors found that all values exceeded the prescribed value 0.5 . The criterion $C R>A V E$ was also met for all constructs. The VIF of all constructs was less than 1.6, the criterion of low multicollinearity was met.

When checking discriminant validity the criteria $M S V<A V E$ and $A S V<A V E$ was considered. These results indicate that we can accept discriminant validity for measuring the conceptual model. As the correlation coefficients for all constructs were statistically significant and positive, also the nomological validity was accepted. Modelling the structural 
equation shows that all connections between the constructs were positive and statistically significant, with a rate risk of $p<0.01$. Table I shows the values of the indicators by which the quality of the advanced conceptual model and the consistency of the data with the conceptual model were evaluated.
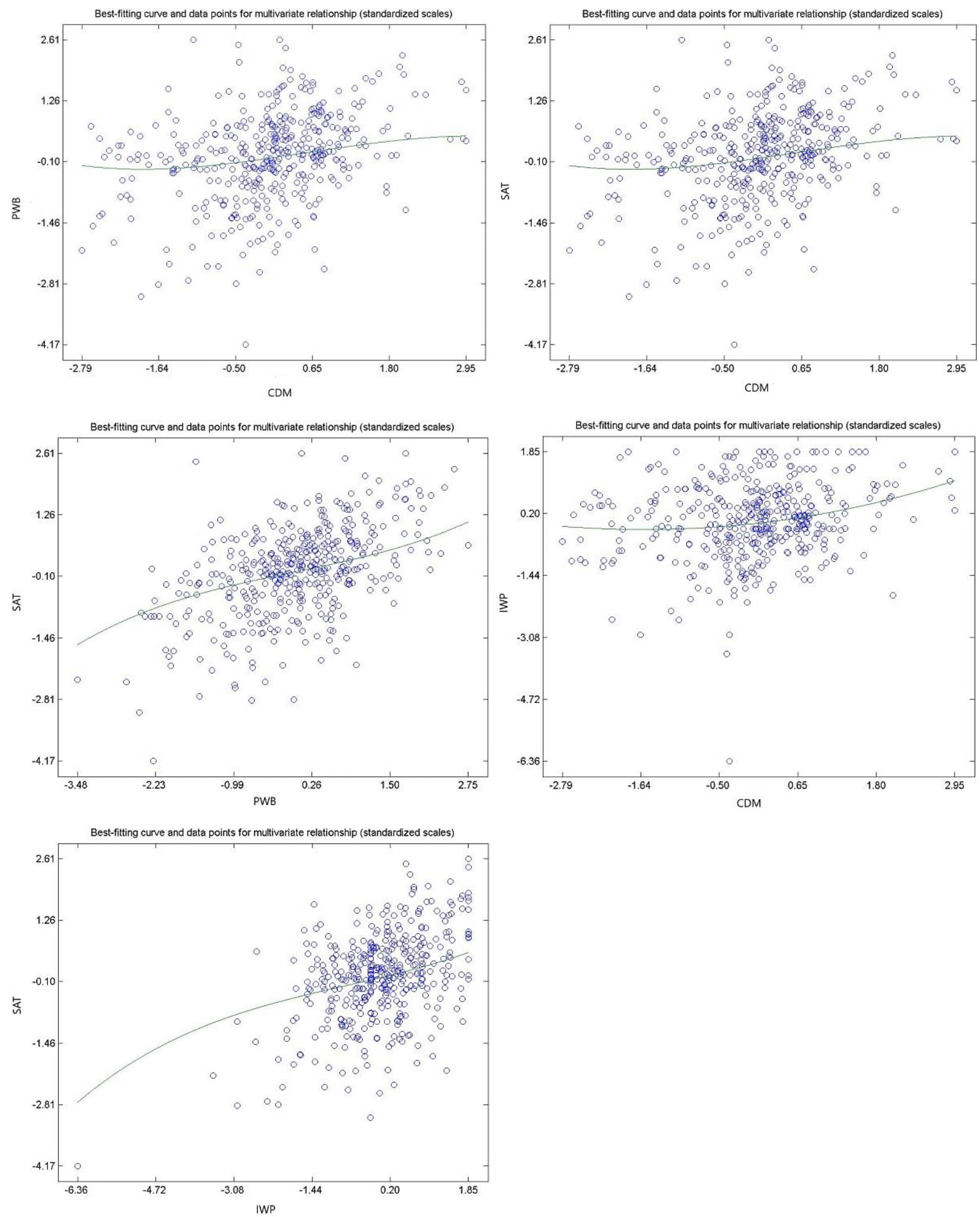

Figure 1: Forms of connections between the constructs of basic conceptual model.

Table I shows that the coefficients of the $A P C, A R S$, and $A A R S$ were statistically significant at $p<0.05$; the coefficient $A V I F$ and $A F V I F$ were below the prescribed values of 
3.3 or 5.0 and were suitable. GoF showed the power of the underlying conceptual model; it was medium powerful $(0.322)$, which shows that the model is moderately appropriate. The values of other coefficients (i.e., SPR, SSR, and NLBCDR) were higher than the prescribed value of 0.7 ; their values were exactly 1.000 . The value of the Simpson's paradox ratio coefficient $(S P R)$ was equal to 1, indicating that no examples of Simpson's paradox existed in the model (see Table I). The results of SEM are presented in Table II.

Table I: Key quality assessment indicators of conceptual model with WarpPLS 5.0.

\begin{tabular}{|l|c|c|}
\hline \multicolumn{1}{|c|}{ Coefficient } & Criterion of coefficients & $\begin{array}{c}\text { Calculated values of } \\
\text { indicators for model }\end{array}$ \\
\hline Average path coefficient $(A P C)$ & $p<0.05$ & 0.285 \\
\hline Average $R$-squared $(A R S)$ & $p<0.05$ & 0.185 \\
\hline Average adjusted $R$-squared $(A A R S)$ & $p<0.05$ & 0.173 \\
\hline Average block variance inflation factor $(A V I F)$ & $A V I F \leq 5.0$ or $A V I F \leq 3.3$ & 1.156 \\
\hline Average full collinearity $(A F V I F)$ & $A F V I F \leq 5.0$ or $A V I F \leq 3.3$ & 1.718 \\
\hline Tenenhaus goodness of fit $(G o F)$ & $\begin{array}{c}G o F \geq 0.1 \text { (low) } \\
G o F \geq 0.25 \text { (medium) } \\
G o F \geq 0.36 \text { (high) }\end{array}$ & 0.322 \\
\hline Simpson's paradox ratio $(S P R)$ & $S P R \geq 0.7$ or $S P R=1.0$ & 1.000 \\
\hline$R$-squared contribution ratio $(R S C R)$ & $R S C R \geq 0.9$ or $R S C R=1.0$ & 1.000 \\
\hline Statistical suppression ration $(S S R)$ & $S S R \geq 0.7$ & 1.000 \\
\hline Nonlinear causality direction ration $(N L B C D R)$ & $N L B C D R \geq 0.7$ & 1.000 \\
\hline
\end{tabular}

Table II: Structural coefficients of basic conceptual model links $(* * p<0.01)$.

\begin{tabular}{|c|c|c|c|c|c|}
\hline $\begin{array}{c}\text { The link between } \\
\text { constructs }\end{array}$ & $\begin{array}{c}\text { Link } \\
\text { direction }\end{array}$ & $\begin{array}{c}\text { Shape of } \\
\text { link }\end{array}$ & $\begin{array}{c}\text { Direct effect } \\
(\boldsymbol{\gamma})\end{array}$ & $\begin{array}{c}\text { Size effect } \\
\left.\boldsymbol{f}^{\mathbf{2}}\right)\end{array}$ & $\begin{array}{c}\text { Standard } \\
\text { error }\end{array}$ \\
\hline $\mathrm{CDM} \rightarrow \mathrm{IWP}$ & + & nonlinear & $0.22^{* *}$ & 0.046 & 0.048 \\
\hline $\mathrm{CDM} \rightarrow \mathrm{PWB}$ & + & nonlinear & $0.41^{* *}$ & 0.159 & 0.046 \\
\hline $\mathrm{CDM} \rightarrow \mathrm{SAT}$ & + & nonlinear & $0.17^{* *}$ & 0.098 & 0.044 \\
\hline $\mathrm{PWB} \rightarrow \mathrm{SAT}$ & + & nonlinear & $0.38^{* *}$ & 0.181 & 0.043 \\
\hline $\mathrm{IWP} \rightarrow \mathrm{SAT}$ & + & nonlinear & $0.32^{* *}$ & 0.147 & 0.042 \\
\hline
\end{tabular}

As it can be seen from the Table II CDM have a positive, statistically significant, and weak impact on IWP $\left(\gamma_{\mathrm{CDM}} \rightarrow \mathrm{IWP}=0.22, p<0.01\right)$. In addition, the strength of the $f^{2}$ effect is greater than $0.02\left(f^{2}=0.046\right)$, that shows that the effect of the predictive latent variable is small.

The CDM have a positive impact on $\operatorname{PWB}\left(\gamma_{\mathrm{CDM}} \rightarrow \mathrm{PWB}=0.41, p<0.01\right)$. The value of Cohen's coefficient $\left(f^{2}=0.159\right)$ shows that the effect of predictive latent variables is of medium strength. The results in Table II show also that CDM positively and statistically significantly affect employee satisfaction $\left(\gamma_{\mathrm{CDM}} \rightarrow \mathrm{SAT}=0.17, p<0.01\right)$. Cohen's coefficient $\left(f^{2}=0.098\right)$ shows that the effect of the predictive latent variable is of medium strength. Furthermore, the results show that PWB positively and statistically significantly affects employees' satisfaction at work $(\gamma \mathrm{PWB} \rightarrow \mathrm{SAT}=0.38, p<0.01)$. Connections between the constructs are nonlinear. Cohen's coefficient $\left(f^{2}=0.181\right)$ shows that the effect of the predictive latent variable is strong. Finally, the results show that IWP positively and statistically significantly affects employees' satisfaction $(\gamma$ IWP $\rightarrow$ SAT $=0.32, p<0.01)$. Cohen's coefficient $\left(f^{2}=0.147\right)$ shows that the effect of the predictive latent variable is of medium strength. 


\section{DISCUSSION}

By modelling structural equations, we found that the connections (influences) between the constructs in the basic conceptual model are nonlinear, as demonstrated by the WarpPLS 5.0. Normally, there are several explanations, based on content and other data, indicating why the links are nonlinear. The reason for that can be interpreted from a quantitative point of view as a consequence of the opinion and the current well-being of the respondents. Each individual can perceive the presented constructs differently, and his/her answers depend on the environment, his/her personality, and his/her experience and other important factors.

The results of the study demonstrated that the connections are statistically significant and mostly positive. Based on the results presented in Table I and Table II all five hypotheses were confirmed. CDM have a weak positive, statistically significant impact on IWP (Hypothesis 1). With the use of CDM, such as coaching, mentoring, sponsorship, and intergenerational cooperation, we can positively influence PWB, individual work performance, and employee satisfaction at work (Hypothesis 2). CDM positively and statistically significantly affect employee satisfaction (Hypothesis 3). Hypothesis 4 was confirmed as PWB has positive and statistically significant impact on employee satisfaction at work. Finally, Hypothesis 5 was confirmed with proven positive and statistically significant connection between IWP and employees' satisfaction.

Results of the study are in line with some other studies. According to [15, 17-18] CDM positively impacts on IWP, job satisfaction, and PWB. IWP has a positive impact on employees' job satisfaction and PWB has a positive impact on job satisfaction $[14,20]$. Individuals who are more individually successful in their work are also more satisfied at the workplace. The psychological well-being of employees at the workplace positively affects their satisfaction at the workplace [17].

In the following Fig. 2 the conceptual model with connections between the constructs is presented.

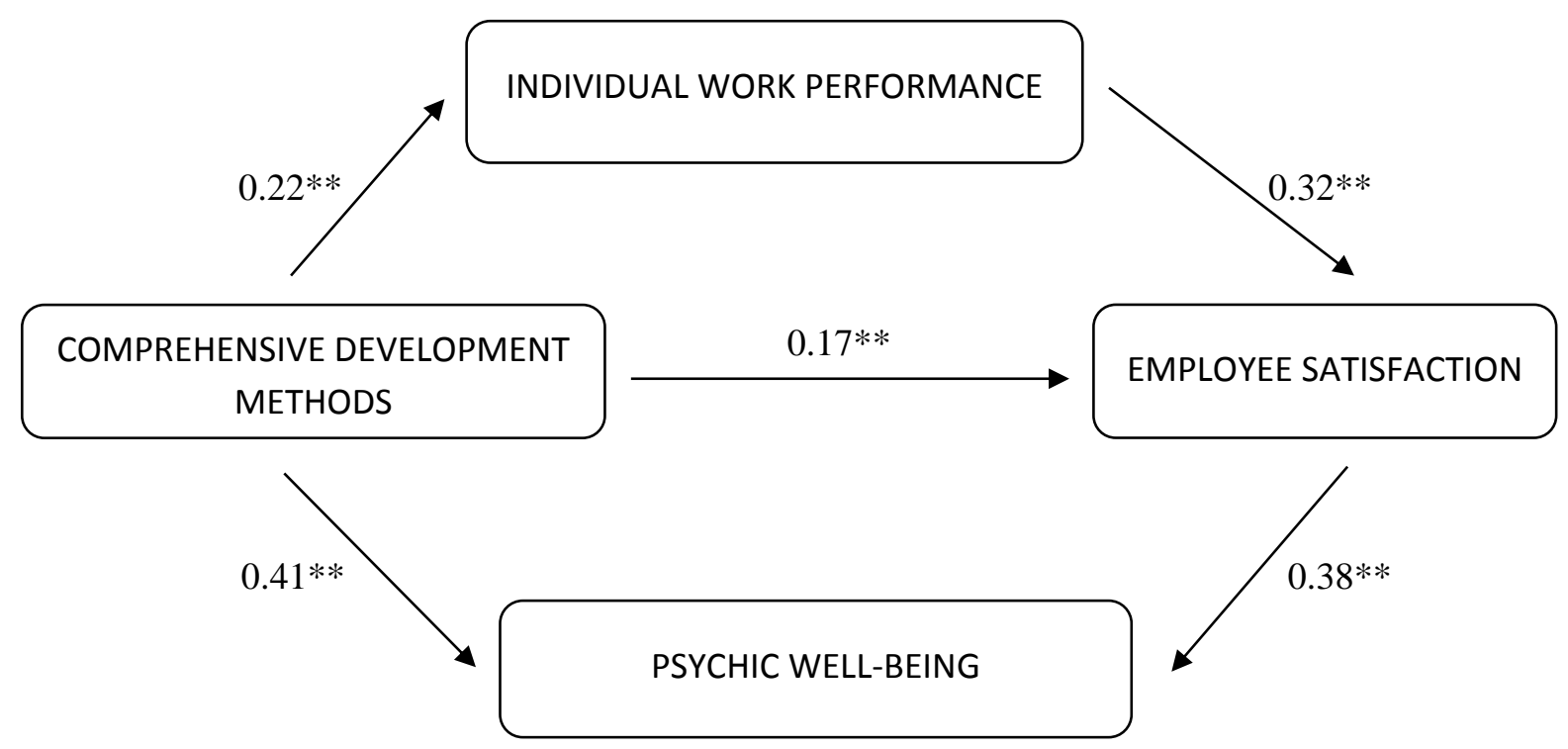

Figure 2: Conceptual model with connections between the constructs $(* * p<0.01)$.

The results of the study raise awareness of employees and management about the inadequacy of existing performance management systems. Consequently, it is necessary to place this knowledge of the situation and trends in the field of IWP as the basis for sensible management action and the introduction of new performance management systems based on a holistic approach, where the focus is on the individual and his/her performance, not on the 
performance management system. Businesses need to adjust their performance management systems to the developmental cycle and not derive information from an annual performance assessment of employees. At the forefront of the new IWP system is a change in leadership style [31], as traditional performance management systems that are closely linked to transaction management, where performance is rewarded and failure is sanctioned, no longer work. Therefore, it is also necessary to move in the direction of a holistic approach to employees, such as transformational, authentic, or health-friendly leadership, which is closely linked to the concept of "healthy" employees and healthy jobs.

The initial step of introducing the new IWP management system should be the design of an internal communication system based on continuous feedback and informal interviews between employees and managers, with a focus on the social recognition of the individual and the use of the CDM.

\section{CONCLUSION}

The research results show that the quality of the conceptual model obtained with WarpPLS 5.0 supports the consideration of nonlinear connections between constructs. Furthermore, it can be concluded that significant nonlinear connections exist between the constructs of the conceptual model of the individual performance management system of employees in the Slovenian service sector. As the considered constructs were psychological constructs, we can explain the cause of nonlinearity in quantitative terms because of the current opinion and well-being of individual respondents. Persons can perceive the presented constructs differently and, therefore, the environment, the personality of respondents, and their experience, and other relevant factors influence the answers.

The design of the employee performance model, which is individual-oriented and based on methods on mentoring, coaching, sponsorship and intergenerational cooperation, contributes to the understanding of how we can use comprehensive employee development methods (CDM) to positively influence individual performance, job satisfaction, and wellbeing of employees. The model is not based on the output or work results of the individual, as in current employee performance management models, but focuses on the individual's input that is, on improving skills and competences by using comprehensive development methods.

The results of this research will significantly contribute to the enrichment and implementation of individual work performance (IWP) management systems and will focus the attention of organizations on the integrated and uniform use of CDM for the development of individuals and the organization as a whole. The most important research limitations are the authors' own measurement instruments about CDM. The authors investigated only service-sector companies, not all sectors. It would certainly be worthwhile to apply the presented IWP model to other industries. Furthermore, an opportunity for further research can be also in designing the national psychic well-being (PWB) indices of individuals as employees, investigating the impact of the holistic IWP model using CDM, and examining the links between neuroscience and CDM.

\section{REFERENCES}

[1] Garr, S. S. (2011). The Performance Management Framework Evolving Performance Management to Fit the Modern Workforce, Bersin \& Associates, Oakland

[2] Koopmans, L.; Bernaards, C. M.; Hildebrandt, V. H.; Schaufeli, W. B.; de Vet, H. C. W.; van der Beek, A. J. (2011). Conceptual frameworks of individual work performance: A systematic review, Journal of Occupational and Environmental Medicine, Vol. 53, No. 8, 856-866, doi:10.1097/JOM.0b013e318226a763 
[3] Widyastuti, T.; Hidayat, R. (2018). Adaptation of Individual Work Performance Questionnaire (IWPQ) into Bahasa Indonesia, International Journal of Research Studies in Psychology, Vol. 7, No. 2, 101-112, doi:10.5861/ijrsp.2018.3020

[4] Koopmans, L.; Bernaards, C. M.; Hildebrandt, V. H.; de Vet, H. C. W.; van der Beek, A. J. (2014). Construct validity of the Individual Work Performance Questionnaire, Journal of Occupational and Environmental Medicine, Vol. 56, No. 3, 331-337, doi:10.1097/ JOM.0000000000000113

[5] Armstrong, M. (2015). Armstrong's Handbook of Performance Management: An Evidence-Based Guide to Delivering High Performance, $5^{\text {th }}$ edition, Kogan Page, London

[6] Murphy, W.; Kram, K. E. (2014). Strategic Relationships at Work: Creating Your Circle of Mentors, Sponsors, and Peers for Success in Business and Life, McGraw-Hill, New York

[7] Allen, T. D.; Eby, L. T. (Eds.) (2007). The Blackwell Handbook of Mentoring: A Multiple Perspectives Approach, Blackwell Publishing, Malden

[8] Kooij, D. T. A. M.; Guest, D. E.; Clinton, M.; Knight, T.; Jansen, P. G. W.; Dikkers, J. S. E. (2013). How the impact of HR practices on employee well-being and performance changes with age, Human Resource Management Journal, Vol. 23, No. 1, 18-35, doi:10.1111/17488583.12000

[9] Magnier-Watanabe, R.; Uchida, T.; Orsini, P.; Benton, C. (2017). Organizational virtuousness and job performance in Japan: does happiness matter?, International Journal of Organizational Analysis, Vol. 25, No. 4, 628-646, doi:10.1108/IJOA-10-2016-1074

[10] Gonçalves, S. P.; Neves, J. (2012). The link between perceptions of human resource management practices and employee well-being at work, Advances in Psychology Study, Vol. 1, No. 1, 31-39

[11] Böckerman, P.; Bryson, A.; Ilmakunnas, P. (2012). Does high involvement management improve worker wellbeing?, Journal of Economic Behavior \& Organization, Vol. 84, No. 2, 660-680, doi:10.1016/j.jebo.2012.09.005

[12] Jayasuriya, R.; Whittaker, M.; Halim, G.; Matineau, T. (2012). Rural health workers and their work environment: the role of inter-personal factors on job satisfaction of nurses in rural Papua New Guinea, BMC Health Services Research, Vol. 12, Paper 156, 12 pages, doi: 10.1186/14726963-12-156

[13] Wright, T. A.; Cropanzano, R.; Bonett, D. G. (2007). The moderating role of employee positive well being on the relation between job satisfaction and job performance, Journal of Occupational Health Psychology, Vol. 12, No. 2, 93-104, doi:10.1037/1076-8998.12.2.93

[14] Ismail, H. N.; Karkoulian, S.; Kertechian, S. K. (2019). Which personal values matter most? Job performance and job satisfaction across job categories, International Journal of Organizational Analysis, Vol. 27, No. 1, 109-124, doi:10.1108/IJOA-11-2017-1275

[15] Kraimer, M. L.; Seibert, S. E.; Wayne, S. J.; Liden, R. C.; Bravo, J. (2011). Antecedents and outcomes of organizational support for development: The critical role of career opportunities, Journal of Applied Psychology, Vol. 96, No. 3, 485-500, doi:10.1037/a0021452

[16] Jones, R. J.; Woods, S. A.; Guillaume, Y. R. F. (2016). The effectiveness of workplace coaching: A meta-analysis of learning and performance outcomes from coaching, Journal of Occupational and Organizational Psychology, Vol. 89, No. 2, 249-277, doi:10.1111/joop.12119

[17] Mali, P.; Kuzmanovic, B.; Nikolic, M.; Mitic, S.; Terek, E. (2019). Model of leadership and entrepreneurial intentions among employed persons, International Journal of Simulation Modelling, Vol. 18, No. 3, 385-396, doi:10.2507/IJSIMM18(3)471

[18] Boyatzis, R. E.; Smith, M. L.; Beveridge, A. J. (2013). Coaching with compassion: inspiring health, well-being, and development in organizations, The Journal of Applied Behavioral Science, Vol. 49, No. 2, 153-178, doi:10.1177/0021886312462236

[19] Robbins, S. P.; Judge, T. A. (2012). Organizational Behavior, $15^{\text {th }}$ edition, Prentice Hall / Pearson Education, Inc., Upper Saddle River

[20] Huang, L.-C.; Ahlstrom, D.; Lee, A. Y.-P.; Chen, S.-Y.; Hsieh, M.-J. (2016). High performance work systems, employee well-being, and job involvement: an empirical study, Personnel Review, Vol. 45, No. 2, 296-314, doi:10.1108/PR-09-2014-0201

[21] Bakotić, D. (2016). Relationship between job satisfaction and organisational performance, Economic Research - Ekonomska istraživanja, Vol. 29, No. 1, 118-130, doi:10.1080/ $\underline{1331677 X .2016 .1163946}$ 
[22] Taba, M. I. (2018). Mediating effect of work performance and organizational commitment in the relationship between reward system and employees' work satisfaction, Journal of Management Development, Vol. 37, No. 1, 65-75, doi:10.1108/JMD-11-2016-0256

[23] Jalagat Jr., R. C. (2016). Performance in CPA board examination: benchmarking for opportunities to meet market demands, International Journal of Social Science and Economic Research, Vol. 1, No. 9, 1350-1381

[24] Dos Santos Matos, L.; Rolim Ensslin, S.; Ensslin, L. (2019). A review on the performance measurement systems life cycle, Lex Localis - Journal of Local Self-Government, Vol. 17, No. 4, 939-959, doi:10.4335/17.4.939-959(2019)

[25] Weiss, D. J.; Dawis, R. V.; England, G. W.; Lofquist, L. H. (1967). Manual for the Minnesota Satisfaction Questionnaire, Minnesota Studies in Vocational Rehabilitation series, Vol. 22, Industrial Relations Center, University of Minnesota, Minneapolis

[26] Watson, D.; Clark, L. A.; Tellegen, A. (1988). Development and validation of a brief measure of positive and negative affect: The PANAS scales, Journal of Personality and Social Psychology, Vol. 54, No. 6, 1063-1070, doi:10.1037/0022-3514.54.6.1063

[27] Ryff, C. D. (1989). Happiness is everything, or is it? Explorations on the meaning of psychological well-being, Journal of Personality and Social Psychology, Vol. 57, No. 6, 10691081, doi: $10.1037 / 0022-3514.57 .6 .1069$

[28] Diener, E.; Emmons, R. A.; Larsen, R. J.; Griffin, S. (1985). The satisfaction with life scale, Journal of Personality Assessment, Vol. 49, No. 1, 71-75, doi:10.1207/s15327752jpa4901_13

[29] Ryan, R. M.; Deci, E. L. (2001). On happiness and human potentials: A review of research on hedonic and eudaimonic well-being, Annual Review of Psychology, Vol. 52, 141-166, doi:10.1146/annurev.psych.52.1.141

[30] Šebjan, U. (2015). Kritični dejavniki uporabe informacijskih rešitev analitičnega upravljanja odnosov s strankami (Eng.: Critical factors of analytical customer relationship management information solutions use), Doctoral dissertation, Faculty of Economics and Business, University of Maribor, Maribor

[31] Strukan, E.; Nikolić, M.; Sefić, S. (2017). Impact of transformational leadership on business performance, Technical Gazette, Vol. 24, Suppl. 2, 435-444, doi:10.17559/TV-20150624082830 